Article

\title{
Formosolv Pretreatment to Fractionate Paulownia Wood Following a Biorefinery Approach: Isolation and Characterization of the Lignin Fraction
}

\author{
Elena Domínguez ${ }^{1}$, Pablo G. del Río ${ }^{2,3}$ (), Aloia Romaní ${ }^{4}$, Gil Garrote ${ }^{2,3}$, Patricia Gullón ${ }^{2, *}$ and \\ Alberto de Vega ${ }^{5}$ \\ 1 Technological Centre of Multisectorial Research (CETIM), Business Park of Alvedro, 15181 Culleredo, Spain; \\ edominguez@cetim.es \\ 2 Department of Chemical Engineering, Faculty of Science, Universidade de Vigo (Campus Ourense), \\ As Lagoas, 32004 Ourense, Spain; pdelrio@uvigo.es (P.G.d.R.); gil@uvigo.es (G.G.) \\ 3 Environmental Technology and Assessment Laboratory, Campus da Auga-Campus Ourense, \\ Universidade de Vigo, 32004 Ourense, Spain \\ 4 Center of Biological Engineering, University of Minho, Campus of Gualtar, 4710057 Braga, Portugal; \\ aloia@ceb.uminho.pt \\ 5 Group of Environmental Chemical Engineering (EnQA), Centro de Investigacións Científicas \\ Avanzadas (CICA), Dept. of Chemistry, Faculty of Science, Univerdade da Coruña, As Carballeiras, s/n, \\ 15071 A Coruña, Spain; alberto.de.vega@udc.es \\ * Correspondence: pgullon@uvigo.es
}

Received: 28 July 2020; Accepted: 13 August 2020; Published: 17 August 2020

\begin{abstract}
Paulownia is a rapid-growth tree with a high biomass production rate per year and low demand of water, which make it very suitable for intercropping systems, as it protects the crops from adverse climatic conditions, benefiting the harvest yields. Moreover, these characteristics make Paulownia a suitable raw material able to be fractionated in an integrated biorefinery scheme to obtain multiple products using a cascade conversion approach. Different delignification pretreatments of biomass have been purposed as a first stage of a lignocellulosic biorefinery. In this study, the formosolv delignification of Paulownia wood was investigated using a second order face-centered factorial design to assess the effects of the independent variables (concentrations of formic and hydrochloric acids and reaction time) on the fractionation of Paulownia wood. The maximum delignification achieved in this study (78.5\%) was obtained under following conditions: $60 \mathrm{~min}$, and $95 \%$ and $0.05 \%$ formic and hydrochloric acid, respectively. In addition, the remained solid phases were analyzed to determine their cellulose content and cooking liquors were also chemically analyzed and characterized. Finally, the recovered lignin by precipitation from formosolv liquor and the pristine lignin (milled wood lignin) in Paulownia wood were characterized and compared by the following techniques FTIR, NMR, high-performance size-exclusion chromatography (HPSEC) and TGA. This complete characterization allowed verifying the capacity of the formosolv process to act on the lignin, causing changes in its structure, which included both phenomena of depolymerization and condensation.
\end{abstract}

Keywords: organosolv; fractionation; lignin; characterization; Paulownia

\section{Introduction}

The current economic system, based on a linear model, has led to humankind's overreliance on non-renewable fossil resources causing its depletion, besides entailing harmful consequences for the environment, society, economy and health [1]. This global reality is provoking an unsustainable 
situation with consequences still incalculable. In an attempt to mitigate this situation, in recent decades, an unceasing search for alternative strategies has been encouraged to find new and suitable production systems founded in the use of renewable resources as raw material within a biorefinery context. This would suppose a transition from the traditional linear economic model to a circular economy, more efficient and greener, moving the current trend towards a global and sustainable bioeconomy [2].

In this scenario, lignocellulosic materials are promising candidates as feedstock to obtain biofuels, building blocks, bio-chemicals, food additives, adhesives, or cosmetics, among others $[3,4]$. Lignocellulosic materials (LCM) present a three-dimensional and recalcitrant structure mainly composed of cellulose (homopolymer made up of glucose units), hemicelluloses (heteropolymer made up of different sugars) and lignin (aromatic polymer). The integral use of LCM involves a selective separation of its components through fractionation treatments following the biorefinery concept [5]. Therefore, the selection of the adequate fractionation process is key to achieve an efficient utilization of all fractions.

Organic solvent pretreatment (also known as organosolv) is an emerging alternative to conventional pulping processes, since it allows fractionating the LCM into cellulose, lignin, and hemicellulose, with a high purity of all fractions opening the possibility of its integral exploitation [6]. The organosolv fractionation process provides an efficient and clean way of transforming lignocellulose into valuable products, facilitating a subsequent recovery of all the fractions obtained [7]. This kind of treatment uses a mixture of an aqueous organic solvent and water, with or without the addition of a mineral acid, which dissolves most part of the lignin and hemicellulose from the raw material [8]. Moreover, these procedures present interesting advantages such as: easy solvent recovery and recyclability, free sulfur, low-cost investment and environmentally friendly [9].

Short-chain organic acids have been considered good solvents for lignin in the delignification of LCM [10]. Particularly, formic acid has attracted considerable attention as a delignification agent, due to its ability to achieve a selective fractionation of the biomass showing high efficiency, both non-wood, hardwood and softwood biomass [9]. The mixture of LCM and concentrated aqueous solutions of formic acid at boiling temperature, with the addition of small quantities of hydrochloric acid employed as a catalyst, is known as formosolv. In this work, the formosolv treatments were performed at atmospheric pressure in all cases, that is, depending on the composition of the cooking liquor, in the range $105-109^{\circ} \mathrm{C}$. Nevertheless, the temperature and pressure can be raised in order to reduce the time of reaction [9]. This process yields a cellulose rich pulp, an aqueous fraction rich in hemicellulosic sugars and a lignin fraction [11]. Among the LCM, Paulownia species are rapid-growth trees with a high biomass production rate per year (50 t/ha/yr) and a low demand of water, which make it very suitable for intercropping systems as it protects the crops from adverse climatic conditions, benefiting the harvest yields. In addition to its uses as wood to build from plywood for musical instruments, other applications suggested for Paulownia wood include its exploitation as a source for pulp due to its fast development and uniform growth [12].

Several works have reported the use of Paulownia species in a biorefinery framework. For example, Domínguez et al., (2017) [13] subjected P. tomentosa to hydrothermal pretreatment to solubilize the hemicellulosic fraction yielding a solid fraction that was evaluated to obtain bio-ethanol. Gong and Bujanovic (2014) [14] purposed a sequence based on hot water extraction to solubilize most of the hemicelluloses followed by the delignification in acetone/water in the presence of oxygen for the production of cellulose and lignin from P. tomentosa and P. elongata. However, to the best of our knowledge, scarce research has been performed to fractionate Paulownia by formosolv pulping to recover cellulose and lignin.

The resulting cellulose of the fractionation process can be used for the production of pulp, derivatives, nanofibrillated cellulose or fermentable glucose (after the cellulose hydrolysis) depending on its physicochemical properties [14].

Lignin is a polyphenolic amorphous material originated from the random oxidative coupling of three main $p$-hydroxycinnamyl alcohol monomers ( $p$-coumaryl, coniferyl, and sinapyl alcohols), 
which are representative of the $p$-hydroxyphenyl (H-units), guaiacyl (G-units) and syringyl (S-units) phenylpropanoid units, respectively $[15,16]$. Due to its polyphenolic chemical structure, it can be employed in the manufacture of adhesives, epoxy, phenolic resins, and polyolefins, as well as in a variety of novel applications.

The objective of this work was the systematic study of the operational variables of formosolv cooking (concentrations of formic and hydrochloric acids and reaction time) to obtain the highest yield of delignification of Paulownia wood. In addition, a secondary target was to identify the main changes caused during the delignification process on the Paulownia lignin, by means of different analytical methods such as FTIR, NMR, high-performance size-exclusion chromatography (HPSEC) and TGA, comparing with pristine lignin used as reference.

\section{Materials and Methods}

\subsection{Raw Material}

The raw material used in this study was wood coming from a dihybrid species of Paulownia (Paulownia elongata $x$ fortunei), and was provided by Maderas Álvarez Oroza, S.L. located in Foz (Lugo, NW, Spain). The wood was milled in a Wiley mill until the size of a particle smaller than $8 \mathrm{~mm}$, homogenized, and stored in containers with aeration in a cool, dry and dark place until its use.

\subsection{Analysis of Raw Material}

Samples taken from the homogenized lot were milled to a size smaller than $0.5 \mathrm{~mm}$ and analyzed (composition shown in Table 1) using the following methods: extractives (National Renewable Energy Laboratory/Technical Procedure NREL/TP-510-42619, 2008), moisture (NREL/TP-510-42621, 2008), ashes (NREL/TP-510-42622, 2008), and quantitative acid hydrolysis (NREL/ TP-510-42618, 2008).

Table 1. Chemical composition of Paulownia elongata $x$ fortunei wood.

\begin{tabular}{cc}
\hline Component & g/100 g Oven-Dried Paulownia \pm Standard Deviation \\
\hline Glucan & $39.7 \pm 0.97$ \\
Xylan + Galactan + Mannan & $14.7 \pm 0.56$ \\
Arabinan & $1.09 \pm 0.05$ \\
Acetyl groups & $3.30 \pm 0.01$ \\
Klason lignin & $21.9 \pm 0.50$ \\
Extractives & $5.60 \pm 0.01$ \\
Ashes & $0.50 \pm 0.05$ \\
Uronic acids (expressed as glucuronic acid) & $1.30 \pm 0.30$ \\
\hline
\end{tabular}

The liquid phase from quantitative acid hydrolysis was analyzed by high-performance liquid chromatography (HPLC) to quantify the monosaccharides, acetic acid and formic acid (detector, refractive index at $30{ }^{\circ} \mathrm{C}$; column, Aminex $\mathrm{HPX}-87 \mathrm{H}$; mobile phase, $0.01 \mathrm{M} \mathrm{H}_{2} \mathrm{SO}_{4}$; flow rate, $0.6 \mathrm{~mL} / \mathrm{min}$; column temperature $50{ }^{\circ} \mathrm{C}$ ). In this column, xylose, galactose and mannose were co-eluted and therefore, these monosaccharides were quantified together using the notation $(\mathrm{Xyl}+\mathrm{Gal}+\mathrm{Man})$. The concentrations of glucose, $\mathrm{Xyl}+\mathrm{Gal}+\mathrm{Man}$, arabinose and acetic acid, before and after quantitative acid hydrolysis $\left(121^{\circ} \mathrm{C}, 60 \mathrm{~min}, 4 \% \mathrm{H}_{2} \mathrm{SO}_{4}\right)$, were used to calculate the equivalent content of glucan, Xylan + Galactan + Mannan, arabinan and acetyl groups, respectively. The insoluble phase from the quantitative acid hydrolysis was gravimetrically quantified and reported as Klason lignin. Uronic acids were determined using a colorimetric method [17]. Analyses were carried out in quadruplicate.

\subsection{Formosolv Fractionation Process}

Mixtures of Paulownia wood, water and formic acid (80-95\%) at $8 \mathrm{~g}$ liquid/g dry Paulownia wood, were heated to boiling point in $250 \mathrm{~mL}$ Pyrex flasks. When the boiling started, hydrochloric acid was added, taking this as time zero. The selected concentrations of hydrochloric acid were in the range of 0.05 to $0.10 \%$, according to the best results found in previous work $[18,19]$. The mixture was stirred 
at atmospheric pressure along a desired time (30-60 min). Reactions were stopped by removing the flasks from the heating plates and by fast filtration through medium-pore Gooch crucibles to separate the pulp from black liquor. In order to prevent the reprecipitation of lignin on the solids, the pulps were subsequently washed with two formic acid solutions, the first one at the same concentration employed in the pretreatment, and the second one at half of its concentration. Finally, the solids were washed with distilled water until neutral $\mathrm{pH}$ (named Paulownia formosolv pulp, PFP). Pulp yield (PY; g oven-dried pulp/100 g oven-dried Paulownia wood) was determined gravimetrically after being oven-dried. The solids were analyzed as described in Section 2.2. and in addition, they were subjected to kappa number (KN) (Tappi T236) and, intrinsic viscosity (VIS) (Tappi T230) determinations.

The aliquots of the black liquors were subjected to posthydrolysis $\left(121{ }^{\circ} \mathrm{C}, 40 \mathrm{~min}, 4 \% \mathrm{H}_{2} \mathrm{SO}_{4}\right)$ in order to quantify the solubilized hemicelluloses. In addition, another aliquot was employed in theh precipitation assays of the lignin by adding a specific amount of water to the black liquor. Precipitated solids were separated by centrifugation (4200 rpm, $10 \mathrm{~min}$ ), repeatedly washed with water, and centrifuged until the supernatant was neutral. Afterwards, the precipitated lignin (Paulownia formosolv lignin, PFL) was lyophilized and used for structural characterization experiments. The quantitative acid hydrolysis of lignin was carried out following the same procedure as in the previous section (NREL/TP-510-42618, 2008).

\subsection{Experimental Design and Statistical Analysis}

In this study, 17 runs (experiments 1-17 collected in Table 2) were performed in accordance with a face-centered factorial design with three replicates at the central point [20] so as to investigate the effects of the variables: $X_{1}$, cooking time (30-60 min), $X_{2}$, formic acid (FA) concentration (80-95\%) and $\mathrm{X}_{3}$ hydrochloric acid (HA) concentration (0.05-0.10\%). Following the normalization of the independent variables to the range $(-1,1)$, quadratic response surfaces were fitted by least-squares multiple regression (Equation (1)) using an excel statistical module (DOE PRO XL, SigmaZone):

$$
D V=b_{O}+\sum_{j=1}^{3} b_{j} X_{j}+\sum_{j=1, j \leq k}^{3} b_{j k} X_{j} x_{k} a
$$

where DV denotes each of the dependent variables (system responses) studied, and $X_{j}$ and $X_{k}$ are the previously defined normalized variables. The values of $b_{0}, b_{i}$, and $b_{j k}$ represent the fitting parameters calculated by multiple regression between the system responses (DV) and the normalized variables.

Table 2. Design of the experiments used to evaluate the delignification process by the formosolv of Paulownia wood and the main results (all data expressed in an oven dry basis).

\begin{tabular}{|c|c|c|c|c|c|c|c|c|c|c|}
\hline \multirow[b]{2}{*}{ Exp. no. } & \multicolumn{3}{|c|}{ Experimental Variables } & \multicolumn{6}{|c|}{ Pulp Composition } & \multirow{2}{*}{$\begin{array}{c}\text { Liquor } \\
\text { Composition } \\
\text { Xyl+Gal+Man } \\
\text { Dis (\%) }{ }^{3}\end{array}$} \\
\hline & Time (min) & FA $(\%)^{1}$ & HA $(\%)^{1}$ & PY $(\%)^{1}$ & $\mathbf{K N}$ & VIS $(\mathrm{mL} / \mathrm{g})$ & $\mathrm{GnP}(\%)^{2}$ & FAP $(\%)^{2}$ & AGP $(\%)^{2}$ & \\
\hline 1 & 60 & 95 & 0.1 & 45.2 & 32.6 & 605 & 70.4 & 3.2 & 0.9 & 17.4 \\
\hline 2 & 30 & 80 & 0.05 & 54.1 & 42.2 & 361 & 63.5 & 1.9 & 1.9 & 17.9 \\
\hline 3 & 60 & 80 & 0.05 & 49.6 & 38.7 & 607 & 73 & 1.8 & 1.1 & 18.1 \\
\hline 4 & 30 & 80 & 0.1 & 55.1 & 47.9 & 467 & 67.8 & 2.1 & 2 & 17.7 \\
\hline 5 & 60 & 80 & 0.1 & 52.1 & 41.8 & 529 & 60.6 & 1.8 & 1.2 & 18 \\
\hline 6 & 30 & 95 & 0.1 & 49.6 & 37.1 & 653 & 63.5 & 3.6 & 1.1 & 17 \\
\hline 7 & 45 & 87.5 & 0.075 & 48.9 & 39.7 & 613 & 65 & 2.3 & 1.1 & 17.8 \\
\hline 8 & 45 & 87.5 & 0.075 & 48 & 40 & 611 & 65.1 & 2.3 & 1 & 17.8 \\
\hline 9 & 45 & 87.5 & 0.075 & 49.4 & 40.4 & 613 & 65.2 & 1.5 & 1.2 & 18.3 \\
\hline 10 & 30 & 95 & 0.05 & 56 & 52.8 & 600 & 66.7 & 6.9 & 2.3 & 14.3 \\
\hline 11 & 60 & 95 & 0.05 & 47 & 27.7 & 626 & 71.7 & 5.8 & 2.4 & 15.9 \\
\hline 12 & 30 & 87.5 & 0.075 & 52.3 & 39.9 & 686 & 64.7 & 2.7 & 1.6 & 17.4 \\
\hline 13 & 60 & 87.5 & 0.075 & 50.6 & 45.7 & 640 & 69.4 & 2.4 & 0 & 17.7 \\
\hline 14 & 45 & 80 & 0.075 & 58.3 & 48.9 & 532 & 61.8 & 6.1 & 0 & 14.8 \\
\hline 15 & 45 & 95 & 0.075 & 51.8 & 40.4 & 617 & 69.6 & 2.2 & 2.9 & 17.7 \\
\hline 16 & 45 & 87.5 & 0.05 & 55.7 & 52.7 & 595 & 67.3 & 7.3 & 0 & 14.2 \\
\hline 17 & 45 & 87.5 & 0.1 & 54.4 & 46.8 & 556 & 69.8 & 6.8 & 0 & 14.6 \\
\hline
\end{tabular}

PY: Pulp yield KN: kappa number; VIS: viscosity; FA: formic acid concentration; HA: hydrochloric acid concentration; GnP: glucan remaining in pulp; FAP: formic acid remaining in pulp; AGP: acetyl groups remaining in pulp; $\mathbf{X y l + G a l + M a n ~ d i s : ~ x y l o s e , ~ g a l a c t o s e , ~ a n d ~ m a n n o s e ~ d i s s o l v e d ~ i n ~ l i q u o r . ; ~}{ }^{1} \mathrm{~kg}$ pulp/100 $\mathrm{kg}$ raw material;

${ }^{2} \mathrm{~kg}$ component $/ 100 \mathrm{~kg}$ pulp; ${ }^{3}$ percentage over content of component in Paulownia wood. 


\subsection{Milled Wood Lignin (MWL) Isolation}

To compare the lignin recovered by the formosolv process with the pristine lignin in Paulownia wood, the milled wood lignin was prepared according to methods as previously described [21,22]. Milled Paulownia wood from an IKA WERKE MF 10 grinder (particle size $<1 \mathrm{~mm}$ ) was subjected to several steps, as follows: (i) extraction with acetone for $8 \mathrm{~h}$ in Soxhlet and with hot water $\left(100^{\circ} \mathrm{C}\right)$ during $3 \mathrm{~h}$, (ii) milling in a Retsch PM 400 centrifugal ball mill with toluene using an agate jar and balls, (iii) three consecutive extractions $(12 \mathrm{~h})$ with dioxane:water $(9: 1, v / v)(25 \mathrm{~mL}$ of solvent/g of milled wood), (iv) the separation of the supernatant by centrifugation and evaporation at $40{ }^{\circ} \mathrm{C}$ at reduced pressure until dryness, (v) the residue obtained (raw MWL) was redissolved in a mixture of acetic acid:water $(9: 1, v / v)(20 \mathrm{~mL}$ of solvent/g of raw MWL), (vi) precipitated in water and separated by centrifugation, (vii) milled in an agate mortar, (viii) dissolved in a solution of 1,2-dicloroethane:ethanol $(1: 2, v / v)$, (ix) the mixture was then centrifuged to eliminate the insoluble material, precipitating the supernatant in diethyl ether and separating the residue obtained by centrifugation, $(\mathrm{x})$ this residue was then resuspended in petroleum ether and centrifuged again to obtain the final purified MWL fraction, which was dried under a $\mathrm{N}_{2}$ current. The final yield was ca. $20 \%$ of the original Klason lignin content.

\subsection{Infrared Spectroscopy (FTIR-ATR)}

FTIR spectra were obtained on a Perkin-Elmer Spectrum 2000 instrument by the attenuated total reflectance (ATR) technique. The spectra were recorded in the $4000-600 \mathrm{~cm}^{-1}$ range with 16 scans at a resolution of $4.0 \mathrm{~cm}^{-1}$ and an interval of $1.0 \mathrm{~cm}^{-1}$ [23]. All the spectra were baseline corrected and normalized in an area, in order to make adequate comparisons.

\subsection{Nuclear Magnetic Resonance (NMR) Spectroscopy}

${ }^{1} \mathrm{H}$ NMR, ${ }^{13} \mathrm{C}$ NMR and HSQC (heteronuclear single quantum correlation) solution state analysis were performed on lignin samples ( $\sim 40 \mathrm{mg}$ ) dissolved on $1 \mathrm{~mL}$ of DMSO- $\mathrm{d}_{6}$. The spectra were recorded at $25^{\circ} \mathrm{C}$ on a Bruker Advance instrument at $500 \mathrm{MHz}$. Standard Bruker programs such as zg30 for ${ }^{1} \mathrm{H}$ NMR, zgpg60 for ${ }^{13} \mathrm{C}$ NMR, and hsqcetgp for HSQC, were used.

For ${ }^{31} \mathrm{P} \mathrm{NMR}$, the samples were derivatized with a phosphitylation reagent according to the procedures previously described [24-27]. Lignin $(20 \mathrm{mg})$ was first dissolved in $500 \mu \mathrm{L}$ of a mixture of pyridine and deuterated chloroform $(1.6: 1 \mathrm{v} / \mathrm{v})$. Afterwards, $100 \mu \mathrm{L}$ of cholesterol $(10 \mathrm{mg} / \mathrm{mL})$ and $100 \mu \mathrm{L}$ of chromium (III) acetylacetonate solution $(5 \mathrm{mg} / \mathrm{mL})$ were added, as an internal standard and relaxation agent, respectively. Finally, the solution was mixed with $100 \mu \mathrm{L}$ of 2-chloro-4,4,5,5-tetramethyl-1,3,2-dioxaphospholane (agent of phosphitylation) for about $10 \mathrm{~min}$ and transferred into a $5 \mathrm{~mm}$ NMR tube for subsequent NMR analysis at $25^{\circ} \mathrm{C}$ on a Bruker Avance $400 \mathrm{MHz}$ instrument using the pulse program zgig (inverse gated decoupling).

In the aliphatic oxygenated region of the HSQC spectra, the relative abundance of interunit linkages were estimated using the volume integrals from the $\mathrm{C}_{\alpha}-\mathrm{H}_{\alpha}$ correlations. In the aromatic region, the $\mathrm{C}_{2,6}-\mathrm{H}_{2,6}$ correlations from $\mathrm{S}$ units and the $\mathrm{C}_{2}-\mathrm{H}_{2}$ from $\mathrm{G}$ units were used to estimate the $\mathrm{S} / \mathrm{G}$ ratio according with previous works [28].

\subsection{High-Performance Size-Exclusion Chromatography (HPSEC)}

The average molecular weight $\left(\mathrm{M}_{\mathrm{w}}\right)$, the number average $\left(\mathrm{M}_{\mathrm{n}}\right)$ and the polydispersity index $\left(\mathrm{M}_{\mathrm{w}} / \mathrm{M}_{\mathrm{n}}\right)$ of MWL and the PFL were analyzed by HPSEC. The chromatography equipment employed was a Jasco LC Net II/ADC (Analog data Can) equipped with a refractive index detector provided with two Varian Polymer Laboratories PolarGel-M columns in series $(300 \mathrm{~mm} \times 7.5 \mathrm{~mm})$. Isolated lignins were dissolved in the mobile phase which consisted in $0.1 \%$ of lithium bromide in dimethylformamide. The chromatographic conditions were as follows: injection volume $20 \mu \mathrm{L}$, a flow of $0.7 \mathrm{~mL} / \mathrm{min}$ and a temperature of $40^{\circ} \mathrm{C}$. The calibration of the SEC was carried out using polystyrene standards with different molecular weights (between 62,500 and $266 \mathrm{~g} / \mathrm{mol}$ ) provided by Sigma Aldrich. 


\subsection{Thermogravimetric Analysis (TGA)}

TGA was carried out on a NETZSH STA 449 F3 Jupiter instruments to investigate the general characteristics of lignin thermal decomposition. A sample of approximately $2.5 \mathrm{mg}$ lignin was loaded into alumina pans, where it was gradually heated from 25 to $900{ }^{\circ} \mathrm{C}$ at a heating rate of $10{ }^{\circ} \mathrm{C} / \mathrm{min}$ under a nitrogen atmosphere with a constant flow of $60 \mathrm{~mL} / \mathrm{min}$. When the Klason lignin was subjected a calcination process, the content of the ashes was negligible.

\subsection{Elemental Analysis}

The $\mathrm{C}, \mathrm{H}$, and $\mathrm{N}$ contents of organosolv lignins were determined in triplicate by elemental analysis in a Flash EA1112 (ThermoFinnigan). The oxygen content was calculated from the difference between the sample weight and the $\mathrm{C}, \mathrm{H}, \mathrm{N}$ and $\mathrm{S}$ contents.

\section{Results and Discussion}

\subsection{Formosolv Process: Delignification of Paulownia Wood}

The formic acid delignification was carried out with the objective to obtain: (i) a high glucan content in the solid phase, potentially useful in later enzymatic hydrolysis stages, (ii) a high delignification degree and (iii) a high solubilization of hemicellulosic sugars, leading to a solid phase mainly composed of glucan.

Paulownia wood was treated with different concentrations of formic and hydrochloric acid. In order to obtain a quantitative description of the effects of these variables on the fractionation process, the experiments were carried out according to a second order face-centered factorial design. The structure of the factorial design, analysis of the pulps and liquors are shown in Table 2, and regression parameters for the variables' solid yield, viscosity and glucan in the pretreated pulp are displayed in Table 3.

Table 3. Regression parameters for the dependent variables: solid yield, viscosity and glucan.

\begin{tabular}{|c|c|c|c|}
\hline & Yield & Viscosity & Gn \\
\hline$b_{0}$ & 51.680 & 619.59 & 65.992 \\
\hline$b_{1}$, Time & $-2.260^{c}$ & $23.94^{c}$ & $1.893^{b}$ \\
\hline $\mathbf{b}_{2}, \mathbf{F A}$ & -1.960 & $60.48^{a}$ & $1.525^{c}$ \\
\hline$b_{3}, \mathrm{HA}$ & -0.600 & 2.12 & -1.026 \\
\hline$b_{12}$ & -0.737 & $-41.31^{b}$ & 1.195 \\
\hline$b_{13}$ & 0.763 & $-32.20^{c}$ & $-1.872^{c}$ \\
\hline$b_{23}$ & -1.463 & 0.52 & 0.452 \\
\hline$b_{123}$ & 0.388 & 13.96 & $2.321^{b}$ \\
\hline$b_{11}$ & -2.415 & 38.04 & 0.404 \\
\hline$b_{22}$ & 1.185 & $-50.75^{c}$ & -0.973 \\
\hline$b_{33}$ & 1.185 & $-49.45^{\mathrm{c}}$ & 1.893 \\
\hline $\mathbf{R}^{2}$ & 0.6738 & 0.918 & 0.8351 \\
\hline
\end{tabular}

a Coefficients significant at $99 \%$ confidence level based on the Student's t-test; ${ }^{\mathrm{b}}$ coefficients significant at $95 \%$ confidence level based on the Student's t-test; ${ }^{c}$ coefficients significant at $90 \%$ confidence level based on the Student's t-test.

Formic acid treatment produced an important solubilization of Paulownia wood, ranging the pulp yield between 45.2 (in experiment 1, carried out at the highest values of the three independent variables, time $=60 \mathrm{~min}, \mathrm{FA}: 95 \%$, HA: $0.1 \%$ ) and $58.3 \%$ (in experiment 14 , time $=45 \mathrm{~min}, \mathrm{FA}: 80 \%$, HA: $0.075 \%$ ). According to the data of Table 2, the yield decreased when the independent variables increased, with more influence of time and FA concentration, according to the data of Table 3.

The highest delignification (78.5\% of lignin removal) was achieved under the conditions of experiment 11 (see Table 2), corresponding to a kappa number value of 27.7 (10.6\% Klason lignin). 
The most significant variables on the results of the $\mathrm{KN}$ were the duration of the treatment and the concentration of formic acid, but none of them were significant at the $95 \%$ confidence level.

Regarding the hemicellulosic sugars recovery in liquors, significant differences were found between the operational conditions, achieving a concentration of hemicellulosic sugars varying in the range of 14.3-18.3 g of sugar/100 $\mathrm{g}$ of Paulownia. The operational range employed allowed to reach very similar percentages of dissolution among the experiments (about $17 \%$ of hemicelluloses were solubilized from Paulownia wood during the pretreatment) (Table 2). In the optimum conditions to remove the maximum lignin content (experiment 11), the distribution of sugars in black liquor was largely dominated by xylooligosaccharides ( $66.9 \%$ of total dissolved carbohydrates, $2.2 \mathrm{~g} / \mathrm{L}$ ), followed by glucooligosaccharides ( $14.3 \%$ of total dissolved carbohydrates, $0.47 \mathrm{~g} / \mathrm{L}$ ) and arabinooligosaccharides ( $7.5 \%$ of total dissolved carbohydrates, $0.24 \mathrm{~g} / \mathrm{L}$ ). The presence of monosaccharides was reduced up to $11.0 \%$ by mass, while their products of decomposition, furfural and hydroxymethylfurfural, only accounted for $0.3 \%$ of the mixture of dissolved carbohydrates.

The high glucan content is directly related to the cellulose purity. In our case, the values were very close to $70 \%$ in the best experimental combinations (experiments $1,3,11$ ). The regression equation of this variable indicates that long treatment times and high FA concentrations promote a high percentage of glucan in pulp. However, the HA concentration must be low as to partially prevent the hydrolytic effects on the cellulose. Figure 1 shows the predicted response surface for the content of glucan in the pulp showing the influences of the more significant variables.

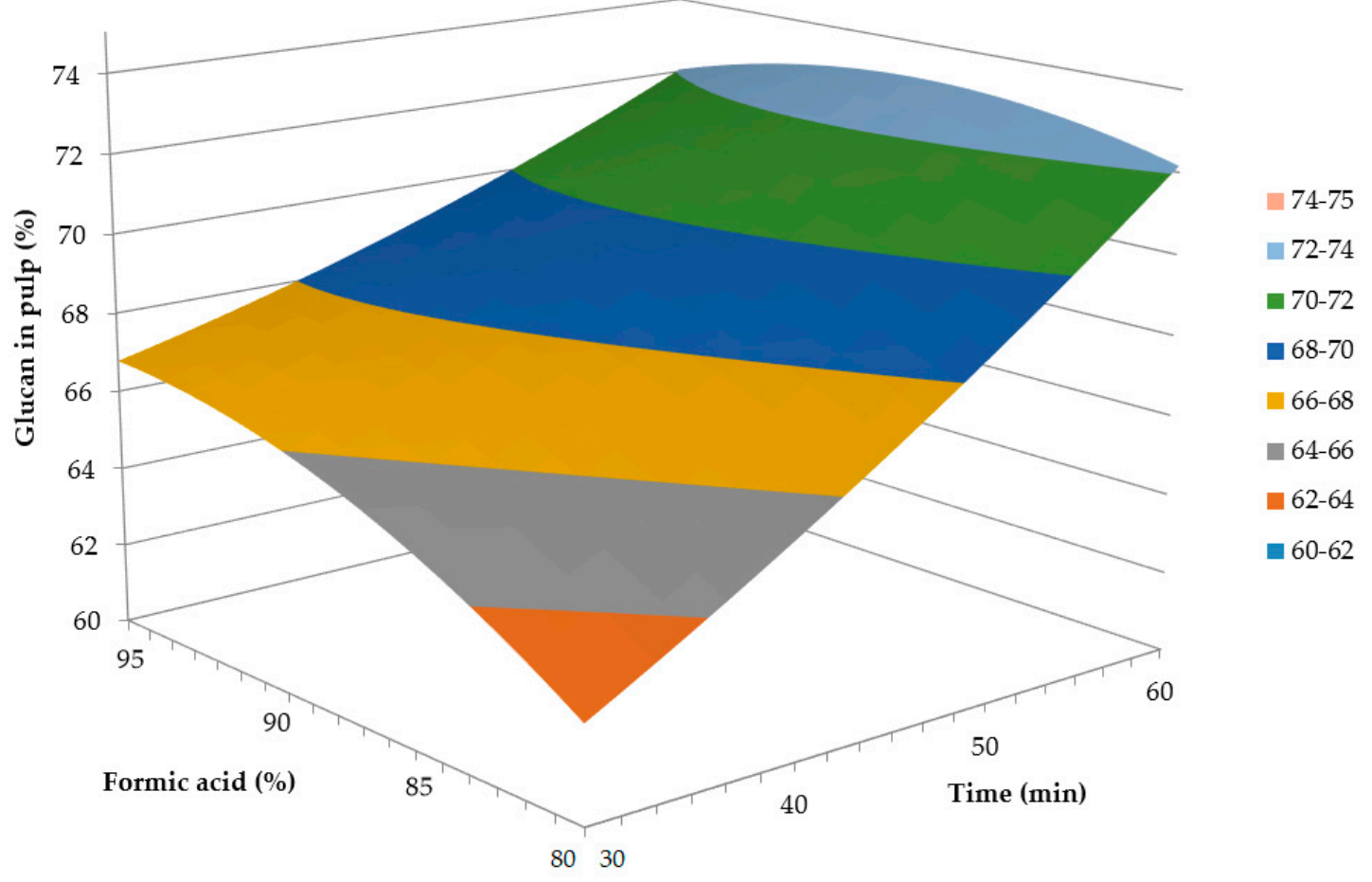

Figure 1. Response surface of glucan in pulp at a constant value of $0.05 \% \mathrm{HA}$.

In order to achieve a more precise information about the severity of the treatment over cellulose, the glucose content of the black liquors was analyzed, as well as the viscosity of the pulps, which is a measure of the chain length of the cellulose. The maximum value of monomeric glucose solubilized from glucan in the liquor was $7.2 \%$ (the average was $4.0 \%$ ), indicating a probable hydrolysis of cellulose to some extent. On the other hand, the viscosities of the pulps, under conditions in which the highest delignification was achieved, were around $600 \mathrm{~mL} / \mathrm{g}$, a relatively low value compared with other pulps with the same KN. It was confirmed that the cellulose suffered a certain attack resulting in a reduction of the chain length. 
It should be noted that the analysis of the formic acid content of the pulps (after quantitative acid hydrolysis) reached a significant mass percentage $(\sim 5 \%)$, probably due to the incorporation of formates in the lignin molecule. This fact was determined by several researchers in different treatments with formic acid $[11,29]$ and is confirmed, in this work, with the spectroscopic data shown below.

A mathematical optimization allowed the definition of the optimal conditions of fractionation introducing, with the same weight, the following constraints for the composition of the pulp: the highest possible content in glucose, the lowest $\mathrm{KN}$ and the lowest content in hemicelluloses. These optimal conditions are a time of $60 \mathrm{~min}$, FA concentration of $95 \%$, and a HA concentration of $0.05 \%$ (experiment 11 ).

\subsection{Precipitation of the Lignin from Formosolv Black Liquor}

In order to collect an adequate amount of lignin for the study of its physicochemical properties, a larger reactor was used at the optimum conditions. The black liquor was treated with different proportions of water to evaluate the precipitation rate as a function of the dilution factor. The curve soon reached an asymptotic value at a dilution factor of $3 \mathrm{~mL}$ water $/ \mathrm{mL}$ liquor. The recovery, gravimetrically measured, was $104 \%$ of the lignin dissolved. This value exceeds $100 \%$ because the solids consisted of not only pure lignin, but also associated carbohydrates $(11 \%)$ and FA (1.6\%).

\subsection{FTIR of Paulownia Wood and Residual Solid}

FTIR spectroscopy is a fast and simple technique that allows extracting valuable information about the existence of functional groups and their changes during chemical treatments. Figure 2 shows the fingerprint region of the FTIR spectra of Paulowia wood (P), and the solid residue after the formosolv treatment (PFP). The assignment of the bands was made based on data published elsewhere $[9,28]$.

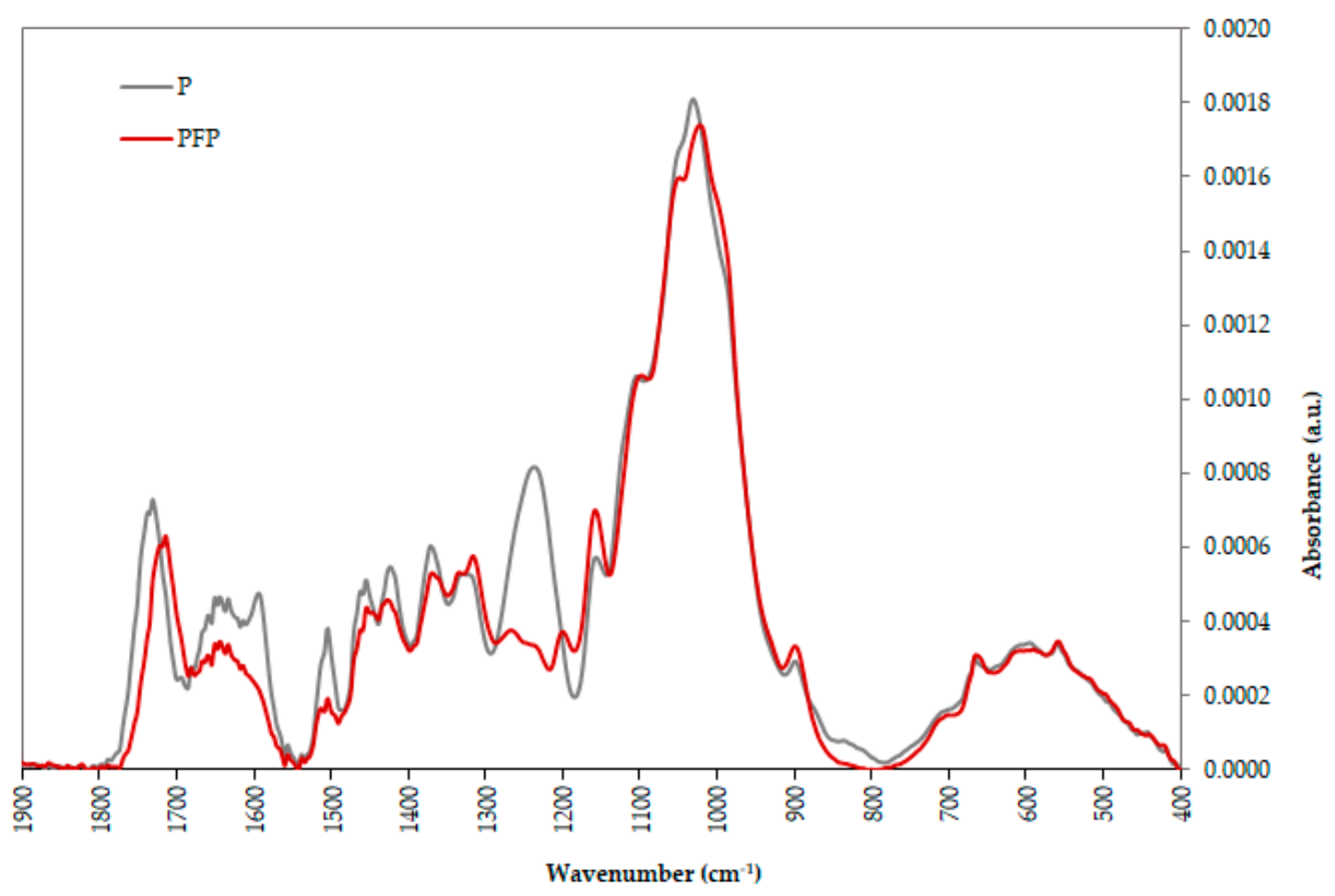

Figure 2. FTIR spectra of Paulowia wood (P) and Paulownia formosolv pulp (PFP).

Several typical bands of lignin can be clearly seen in the spectra, which involve aromatic skeleton vibrations, which disappeared or were greatly diminished in the residual solid of the formosolv treatment due to extensive delignification. For example: 1594, 1504, $1420 \mathrm{~cm}^{-1}$, and the broad 
band around $1230 \mathrm{~cm}^{-1}$ that contains the contributions of vibration modes from $\mathrm{G}$ and $\mathrm{S}$ units. In addition, the band located around $1650 \mathrm{~cm}^{-1}$ reflects some loss of $\mathrm{C}=\mathrm{O}$ conjugate aryl ketones in lignin. The absorption band in the Paulownia wood spectrum at $1730 \mathrm{~cm}^{-1}$, attributable to the presence of acetyl groups of the hemicellulose, disappeared after organosolv treatment, indicating the solubilization of the majority of the hemicellulose. In addition, a new absorption band appeared in the spectrum of formosolv pulp, at lower wavelength $\left(1710 \mathrm{~cm}^{-1}\right)$ that is assigned to the incorporation of formate groups to the propyl chain of lignin [11]. Finally, the bands located at 1325 and $1265 \mathrm{~cm}^{-1}$, originated by the stretching of $\mathrm{C}-\mathrm{O}$ bonds in $\mathrm{S}$ and G-units, respectively, modified their relative intensity in an evident way. Although it is not possible to confirm the exclusive contribution of G-units in the band at $1265 \mathrm{~cm}^{-1}$, its great decrease in intensity seems to indicate an important loss of guaiacyl structures [30].

\subsection{Structural Characterization of Lignins}

${ }^{1} \mathrm{H}$ NMR Spectroscopy of MWL and Formosolv Lignin

Figure S1 shows the ${ }^{1} \mathrm{H}$ NMR spectra of MWL and formosolv Paulownia lignin. The ${ }^{1} \mathrm{H}$ NMR spectra of MWL and PFL showed that the proton signals in non-oxygenated carbons (methyl and methylene groups, $\delta=0.8-1.2 \mathrm{ppm}$ ) were fewer, and less intense in the organosolv residue, which indicates structural modifications in the side chain of the phenylpropane units. The methyl acetate protons resonated in the range of 1.8-2.1 ppm and disappeared almost completely after the treatment, due to the hydrolytic effect of the acidic medium in the black liquor. Peaks at 2.50 and 3.33 ppm were due to residual proton signals in DMSO- $\mathrm{d}_{6}$ and water, respectively [31].

Between 4 and $5.5 \mathrm{ppm}$, a large number of signals originated from several protons of the propyl side chain of lignin. In this region of the spectrum, resonances due to the different protons of the hemicelluloses components also appear, but their contribution should be very low. The areas of these signals are smaller in the organosolv residue, which indicates the changes in the functionalities of the side chain. Specifically, the signal at $4.44 \mathrm{ppm}$ (part per million), which originated from the $\gamma$ protons in $\beta-\mathrm{O}-4^{\prime}$ aryl ether units, decreased drastically in the spectrum of PFL due to delignification.

The range between 6.3 and $7.5 \mathrm{ppm}$ showed the different signals of the aromatic protons, and between 8 and $9 \mathrm{ppm}$ (part per million), those of the phenolic hydroxyl protons. The sharp peak at $8.1 \mathrm{ppm}$ originated from carboxylic functionalities (formic acid) incorporated into a lignin molecule.

\section{5. ${ }^{13}$ C NMR Spectroscopy}

${ }^{13} \mathrm{C}$ NMR spectra of MWL and PFL (Figure 3) provide interesting information about several functional features of MWL and the changes suffered after the organosolv treatment. The assignment of signals was made based on previous published works [32-35].

The spectrum of MWL showed the characteristic peaks assigned to methoxy groups (55.9 ppm), carbonyl carbon in acetates $(169.6 \mathrm{ppm})$, carbons 3 and $5\left(\mathrm{C}_{3,5}\right)$ in etherified syringyl (S) units (152.2 ppm), $C_{3}$ in etherified guaiacyl (G) units (149.1 ppm), $C_{4}$ in etherified $G$ units and $C_{3,5}$ in non-etherified $\mathrm{S}$ units, and $\mathrm{C}_{4}$ in $\mathrm{S}$ units (138.2 ppm). The aromatic carbons 2,5 and 6 of the $\mathrm{G}$ structures resonated at 111.1, 114.7 and $119.1 \mathrm{ppm}$, respectively, while the $C_{2,6}$ in the $S$ units produced a signal around 104 ppm.

Between 70 and $90 \mathrm{ppm}$, the signals of $C_{\beta}$ in $\beta-\mathrm{O}-4^{\prime}$, and $C_{\alpha}$ in $\beta-5$ and $\beta-\beta^{\prime}$ were overlapped with those belonging to the carbons of the residual carbohydrates, complicating an accurate assignment, but probably the sharpest signal in this area $(71.9 \mathrm{ppm})$ could be due to $\mathrm{C}_{\alpha}$ of $\beta-\mathrm{O}-4^{\prime}$ linkages. Other identifiable peaks were: $C_{\gamma}$ in units with oxidized $C_{\alpha}(65.6 \mathrm{ppm}), C_{\gamma}$ in substructures $\beta-\mathrm{O}-4^{\prime}$ (62.9 ppm), methylene carbons in the $\alpha, \beta$ positions of the side chain $(29.1 \mathrm{ppm})$, the methyl carbon in acetates $(21.1 \mathrm{ppm})$, and the primary carbon in methyl groups of the propyl chain (15.3 ppm). The absence of typical $p$-hydroxyphenyl group signals $(167,161,158 \mathrm{ppm})$ agrees with those found in the literature [36,37] and reflects that the Paulownia hardwood lignin is GS-type [35]. 


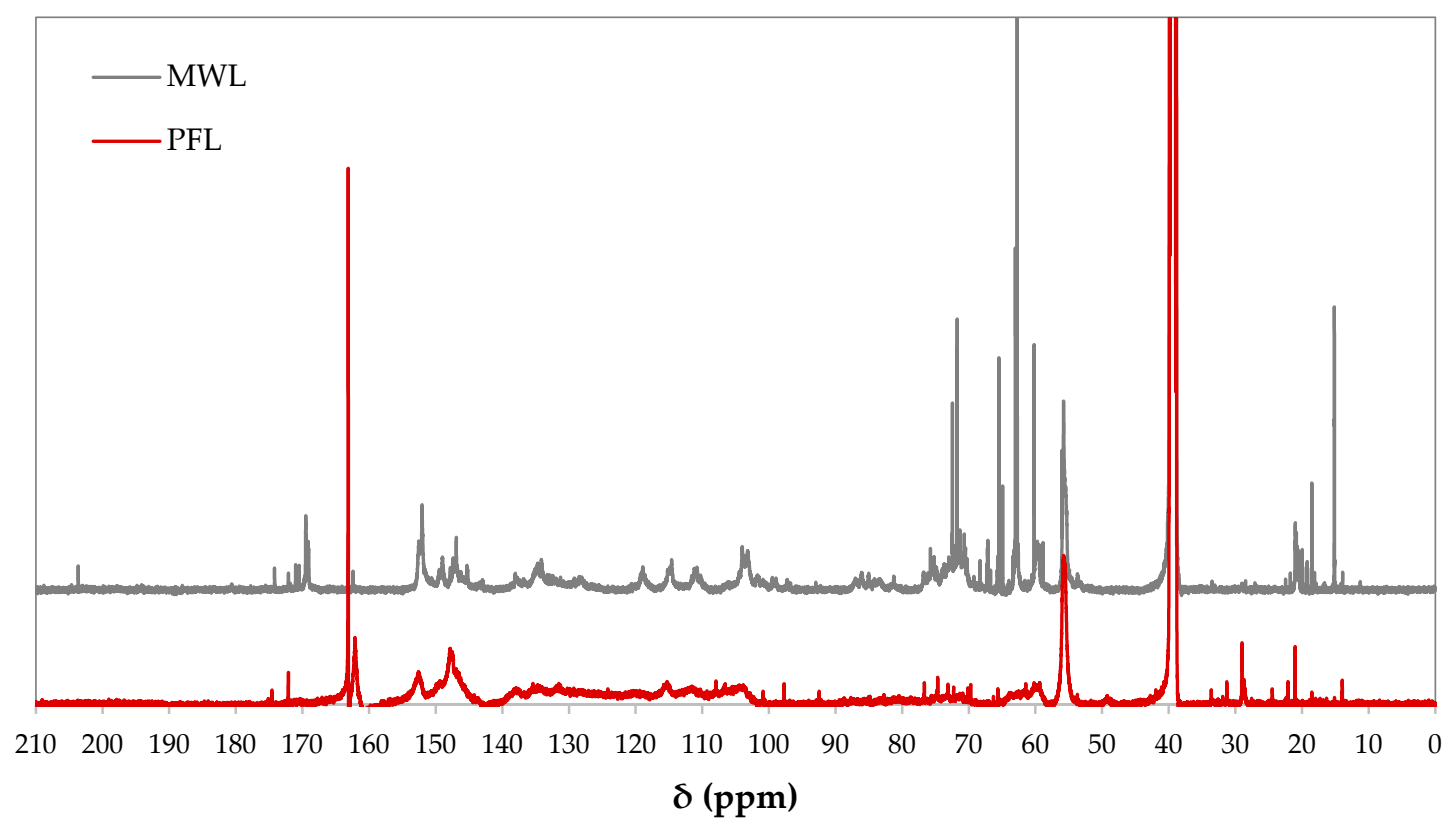

Figure $3 .{ }^{13} \mathrm{C}$ NMR spectra of milled wood lignin (MWL) and Paulownia formosolv lignin (PFL).

After the formosolv treatment, the lignin recovered from the liquor (PFL) showed important changes compared to MWL. The acetate groups were almost completely eliminated from the structure (absence of signals at 169.6 and $21.1 \mathrm{ppm}$ ). At the same time, two intense signals (163.4 and $162.4 \mathrm{ppm}$ ), not appearing in the MWL spectrum, reflected the introduction of formate groups into the molecule [38]. The effects of delignification are clearly reflected in ${ }^{13} \mathrm{C}$ NMR spectrum of PFL. The depolymerization of lignin through the disruption of $\beta-O-4^{\prime}$ bonds and to some extent, $\beta-5^{\prime}$ and $\beta-\beta^{\prime}$, was reflected by the decrease in the intensity of many of the typical signals of these substructures in the 90-52 ppm range: specifically, 71.9, 65.6, and 62.9, whose assignment was mentioned above. Additionally, the solubilization of a large proportion of the remaining carbohydrates in the MWL causes this area of the spectrum to have less signals than MWL. The distribution of aliphatic carbon signals is modified, appearing more and as different types of signals: more methylenic carbons and less methyl groups.

In the region of aromatic carbons (166-102 ppm), the changes produced by delignification were clearly visible. The signals of carbons 2, 5 and 6 in the G-units (111.1, 114.7 and $119.1 \mathrm{ppm}$ ) were broader and with a larger area, which is compatible with a partial recondensation of lignin. In addition, the signals $C_{3,5}$ in the S-units (152.2 ppm) and $C_{3}$ in the G-units (149.1 ppm) increased their intensity. However, this increase was more important in the signal due to guaiacyl groups, indicating a greater tendency of these groups to undergo recondensation processes. The integration of the clusters due to the signals of aryl bonds [33] that is C-O (161-141 ppm), C-C (141-124 ppm) and C-H (124-100 ppm) indicated different percentage between the values of MWL and PFL of $-2 \%, 31 \%$ and $-21 \%$, respectively. These values can be explained by the formation of a higher proportion of $\mathrm{C}-\mathrm{C}$ links and a loss of $\mathrm{C}-\mathrm{H}$, which provide an additional symptom of the existence of lignin condensation reactions.

Table S1 (Supplementary Material) collects the assignments of carbon chemical shifts $(\delta, \mathrm{ppm})$ in the ${ }^{13} \mathrm{C}$ NMR spectrum of MWL and formosolv lignin.

\section{6. ${ }^{1} \mathrm{H}^{-13} \mathrm{C}$ HSQC NMR Spectroscopy of Lignins}

The HSQC spectrum of the MWL of Paulownia wood (Figure 4a,c) shows some prominent signals that allowed to extract information about the most important features on how phenylpropanoid units are linked together. The most important correlations correspond to:

- The C-H correlations in aromatic methoxyl between $\delta_{\mathrm{C}}-\delta_{\mathrm{H}}: 56.1 / 3.2-56.2 / 3.7$; 
- Aryglycerol $\beta$-aryl ether with $\beta-\mathrm{O}-4^{\prime}$ links (label A), which can be seen at $\delta_{\mathrm{C}}-\delta_{\mathrm{H}}: 72.5 / 4.9$ and 71.8/4.7 ( $\mathrm{C}_{\alpha}-\mathrm{H}_{\alpha}$ in $\mathrm{S}$ and G-units respectively), 84.4/4.3 and 86.5/4.1 $\left(\mathrm{C}_{\beta}-\mathrm{H}_{\beta}\right.$ in $\mathrm{S}$ and G-units, respectively) and a broad signal, overlapping with others, in 60.2/3.7-60.4/3.2 $\left(\mathrm{C}_{\gamma}-\mathrm{H}_{\gamma}\right)$;

- Resinol type units $\left(\alpha-\mathrm{O}-\gamma^{\prime}, \beta-\beta^{\prime}\right.$, and $\gamma$-O- $\alpha^{\prime}$ linkages, label B): their different $\mathrm{C}-\mathrm{H}$ correlations are evident at $\delta_{\mathrm{C}}-\delta_{\mathrm{H}}$ : 85.5/4.7 $\left(\mathrm{C}_{\alpha}-\mathrm{H}_{\alpha}\right), 54.3 / 3.1\left(\mathrm{C}_{\beta}-\mathrm{H}_{\beta}\right)$, 71.6/3.8 and 71.7/4.2 $\left(\mathrm{C}_{\gamma}-\mathrm{H}_{\gamma}\right)$;

- Phenylcoumaran type structures $\left(\alpha-\beta-5^{\prime}, \alpha-\mathrm{O}-4^{\prime}\right.$ linkages, label $\left.\mathrm{C}\right)$ : only two types of correlations are visible in the spectrum: $\mathrm{C}_{\alpha}-\mathrm{H}_{\alpha}$ at $\delta_{\mathrm{C}}-\delta_{\mathrm{H}}: 87.5 / 5.5$, and $\mathrm{C}_{\beta}-\mathrm{H}_{\beta}$ at $\delta_{\mathrm{C}}-\delta_{\mathrm{H}}: 53.9 / 3.5$, they are partially overlapped with the correlations of the aromatic methoxyl groups;

- Spirodienone type structures $\left(\beta-1^{\prime}, \alpha-\mathrm{O}-\alpha^{\prime}\right.$ linkages, label D): they present less intense signals at $\delta_{\mathrm{C}}-\delta_{\mathrm{H}}: 81.80 / 5.04\left(\mathrm{C}_{\alpha}-\mathrm{H}_{\alpha}\right.$ correlations), and 60.4/2.7 $\left(\mathrm{C}_{\beta}-\mathrm{H}_{\beta}\right)$;

- A weak signal, due to $\mathrm{C}_{\beta}-\mathrm{H}_{\beta}$ correlation on dibenzodioxocin-like structures (label E), also appears in the spectrum at $\delta_{C}-\delta_{H} 86.6 / 3.8$-however, the one corresponding to the $\mathrm{C}_{\alpha}-\mathrm{H}_{\alpha}$ correlation (83.4/4.8) can only be observed at very low contour levels;

- Low-intensity correlations corresponding to cynnamyl alcohol end-groups $(129.15 / 6.45,128.89 / 6.23$, and 62.06/4.10, correlations between carbonhydrogen $\alpha, \beta$ and $\gamma$, respectively, and label I) and cynnamyl aldehyde end-groups $\left(\mathrm{C}_{\beta}-\mathrm{H}_{\beta}: 126.72 / 6.77\right.$. Label J) are also present;

- In the area of the spectrum corresponding to aromatic $\mathrm{C}-\mathrm{H}$ correlations the signals belonging to $S$ (carbons 2 and $6 \delta_{C}-\delta_{\mathrm{H}}$ 104.4/6.7. label $S_{2,6}$ ) and G-units (111.6/7.0, carbon 2, label G2; 115.5/6.7-115.8/6.9, carbon 5, label G5, and 119.7/6.8, carbon 6, label G6) are predominant-other less intense signals belonging to S-units oxidized in the $\alpha$-carbon $\left(\mathrm{S}_{2,6^{\prime}}\right)$ are also observable at $\delta_{\mathrm{C}}-\delta_{\mathrm{H}}$ 107.1/7.3 and 107.0/7.2;

- Minor signals can be seen due to the cinnamaldehyde end-groups in S-units $\left(\mathrm{J}_{2,6-\mathrm{S}} \mathrm{S}\right)$ at $106.7 / 7.0$ and $\mathrm{H}$-units $\left(\mathrm{H}_{2,6}\right)$ at 128.9/7.2;

- Finally, it is worth mentioning that the presence of associated carbohydrate signals, which are indicated in the figure corresponding to the anomeric positions and some other with acetyl substituents [39].

Table S2 (Supplementary Material) collects the assignments of the ${ }^{13} \mathrm{C}-{ }^{1} \mathrm{H}$ correlation signals in the HSQC NMR spectrum of the obtained lignin fractions.

HSQC spectrum of PFL (Figure $4 \mathrm{~b}, \mathrm{~d}$ ) reflects important structural changes after the treatment. The more apparent difference is the presence of a broad signal (around $\delta_{C}-\delta_{H}$ 63.5/4.3) which corresponds to the $\beta-\mathrm{O}-4^{\prime}$ structures with acylated $\gamma-\mathrm{OH}$, probably as formates. The formylation of the $\gamma-\mathrm{OH}$ was referred by other researchers $[9,28]$ treating LCM with FA solutions of different concentrations and at different temperatures. The ${ }^{13} \mathrm{C}$ NMR spectrum reflected this fact (peaks at 163.4 and $162.4 \mathrm{ppm}$ already mentioned), but also the HSQC spectrum of the PFL showed a signal at $\delta_{\mathrm{C}}-\delta_{\mathrm{H}}$ 162.0/8.2 that confirms the formylation of the lignin.

Table 4 presents the quantification of the different types of linkages according to Sun and coworkers (Sun et al., 2014). In the MWL, $\beta-\mathrm{O}-4^{\prime}$ units were predominant and accounted for $57.6 \%$ of all identified linkages, followed by resinols (21.4\%), phenylcoumarans (9.4\%), and spirodienones (3.7\%). In addition, minor proportions of $p$-hydroxycinnamyl with alcohol (2.2\%) and aldehyde (2.3\%) end-groups were quantified in the spectrum.

All the correlations corresponding to the different linkages between phenylpropane units were drastically diminished in the spectrum of PFL. The effect of delignification, through the destruction of the linkages identified in MWL, is very important. The quantification of this breakdown of bonds was $87 \%$ of the $\beta$-aryl ethers, $78 \%$ of the resinol type subunits, $65 \%$ of the phenylcoumarans and $70 \%$ of the spirodienones. The cinnamyl alcohol or aldehyde-type units completely disappeared in PFL.

Moreover, the signals derived from the aromatic nucleus $\left(G_{2}, G_{5}, G_{6}\right.$ and $\left.S_{2,6}\right)$ were less intense and extended towards smaller chemical shifts in both dimensions, which is indicative of the existence of condensation in the lignin $[9,40]$. 

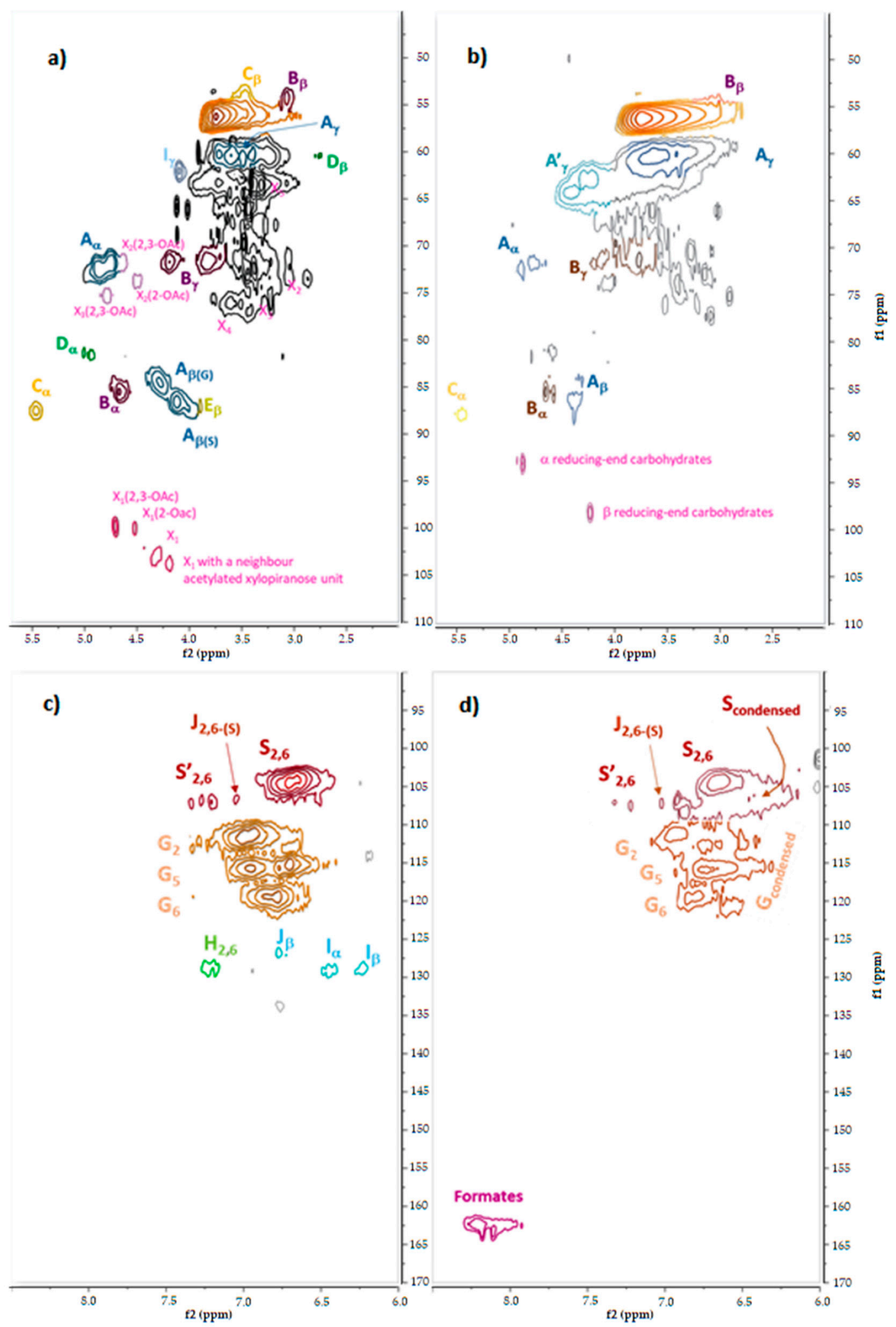

Figure 4. HSQC spectra of MWL $(\mathbf{a}, \mathbf{c})$ and PFL $(\mathbf{b}, \mathbf{d})$. 
Table 4. Properties of MWL and PFL.

\begin{tabular}{|c|c|c|c|}
\hline & & MWL & PFL \\
\hline \multirow{6}{*}{$\begin{array}{l}\text { Structural units/C9 } \\
\text { by HSQC }\end{array}$} & Arylglycerol $\beta-\mathrm{O}-4^{\prime}$ aryl ethers & 0.41 & 0.13 \\
\hline & Resinols & 0.15 & 0.11 \\
\hline & Phenylcoumarans & 0.07 & 0.07 \\
\hline & Dibenzidioxocins & 0.02 & 0 \\
\hline & p-OH-cinnamyl alcohol end-groups & 0.03 & 0 \\
\hline & $p$-OH-cinnamyl aldehyde end-groups & 0.02 & 0 \\
\hline \multirow{4}{*}{$\begin{array}{l}\text { OH groups by }{ }^{31} \mathrm{P} \text { NMR } \\
(\mathrm{mmol} / \mathrm{g})\end{array}$} & $\mathrm{OH}$ in 5-substituted units & 0.17 & 0.83 \\
\hline & Guaiacyl OH & 0.34 & 0.57 \\
\hline & Total OH & 6.16 & 3.6 \\
\hline & Carboxyl (COOH) & 0.01 & 0.23 \\
\hline Elemental analysis $(\%)$ & $\mathrm{C}$ & 55.04 & 59.99 \\
\hline \multirow{3}{*}{ SEC (Da) } & $M_{n}$ & 9145 & 3589 \\
\hline & $\mathrm{M}_{\mathrm{W}}$ & 22792 & 44458 \\
\hline & $\mathrm{D}\left(\mathrm{M}_{\mathrm{n}} / \mathrm{M}_{\mathrm{w}}\right)$ & 2.5 & 12.4 \\
\hline \multirow{4}{*}{ TGA/DTG * } & $\mathrm{T}_{5 \%}\left({ }^{\circ} \mathrm{C}\right)$ & 171 & 251 \\
\hline & Residue at $900^{\circ} \mathrm{C}(\%$ mass $)$ & 35.2 & 53 \\
\hline & $\mathrm{DTG}_{\max }\left(\% /{ }^{\circ} \mathrm{C}\right)$ & 0.31 & 0.29 \\
\hline & $\mathrm{T}$ of DTG $\max \left({ }^{\circ} \mathrm{C}\right)$ & 291 & 370 \\
\hline
\end{tabular}

* DTG: first derivative of the TGA curve.

Table 4 also shows the $\mathrm{S} / \mathrm{G}$ ratio calculated based on the volume integrals of signals $\mathrm{S}_{2,6}$ and $\mathrm{G}_{2}$, according to previously published works [28]. The value of S/G for MWL (0.63) was in accordance to that measured by Rencoret et al. [21] for Paulownia fortunei (0.66). The corresponding value for PFL $(0.83)$ indicated that G-units have suffered more degradation than S-units.

Figure S2 (Supplementary Material) shows the main substructures identified in MWL and PFL of Paulownia.

\section{7. ${ }^{31}$ P NMR Spectroscopy of Lignins}

Figure 5 shows the ${ }^{31} \mathrm{P}$ NMR spectra of the phosphitylated MWL and PFL, and Table 4 shows the calculated distribution of the different $\mathrm{OH}$ groups. According to the bibliography [25-27], the signals can be classified according to the different resonances of each type of the phosphitylated hydroxyl groups present in the molecule (Figure 5). Thus, the signals corresponding to aliphatic $\mathrm{OH}$ (150.6-145.2 ppm) of the PFL decreased very significantly (61\%) after the organosolv treatment. Several mechanisms of esterification (formylation) and acid-catalyzed dehydration can explain this decrease $[6,7,41]$. The signals produced by $\mathrm{G}$ and S-type units were much broader in the PFL due to recondensation, as was also reflected in the HSQC spectra. In fact, the area of signals increased almost four times after the formosolv treatment due to the presences of 5-substituted structures which include syringyl, and $\beta-5^{\prime}, 4-\mathrm{O}-5^{\prime}$ and $5-5^{\prime}$ linked units. The signals due to G-units also showed condensation processes since the spectrum reflected similar qualitatively similar characteristics to those of the S-units. At $135.8 \mathrm{ppm}$ a signal, absent in MWL, appeared due to the formic acid carboxyl group [42]. The spectrum area corresponding to the carboxyl groups (136.3-134.21 ppm) revealed more intense signals in PFL. Table 4 reflects the content of the different hydroxyl, in $\mathrm{mmol} \mathrm{OH} / \mathrm{mg}$ lignin, depending on the content of the internal standard (cholesterol) and according to the methods already published [27]. 


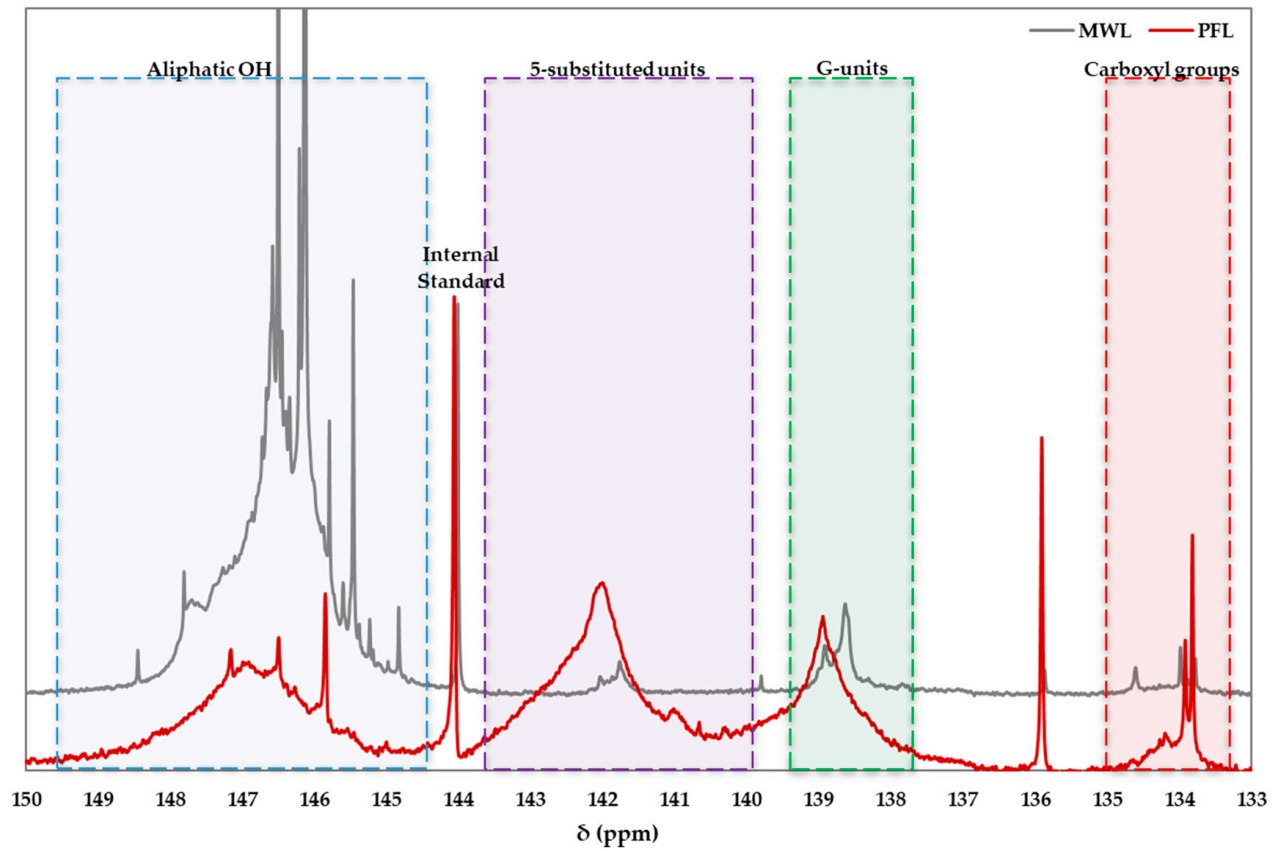

Figure 5. ${ }^{31} \mathrm{P}$ NMR spectra of MWL and PFL.

\subsection{Molecular Weights of Lignins}

The SEC analysis on the lignin samples (Figure 6) was used to evaluate its molecular size distribution. Table 4 shows the most important parameters calculated from the chromatograms. Compared with MWL, the molar mass distribution of PFL showed a lower $M_{n}$ but a higher $M_{w}$. In order to explain this, in PFL a larger number of small and big molecules should be present in relation to MWL; that is, a much higher polydispersity than that of MWL. In fact, it is almost five times higher ( 2.5 vs. 12.4$)$, according to the SEC data. This points out that there was a concurrent depolymerization and recondensation of lignin in the reaction medium. Taking as reference the simple C9 formulas (Table 4) to calculate the molecular mass of each C9 unit and the value of $\mathrm{M}_{\mathrm{w}}$ as an average representative of the lignin molecular size, values of 116.5 and 246.2 units C9/lignin molecule for MWL and PFL, respectively, were calculated.

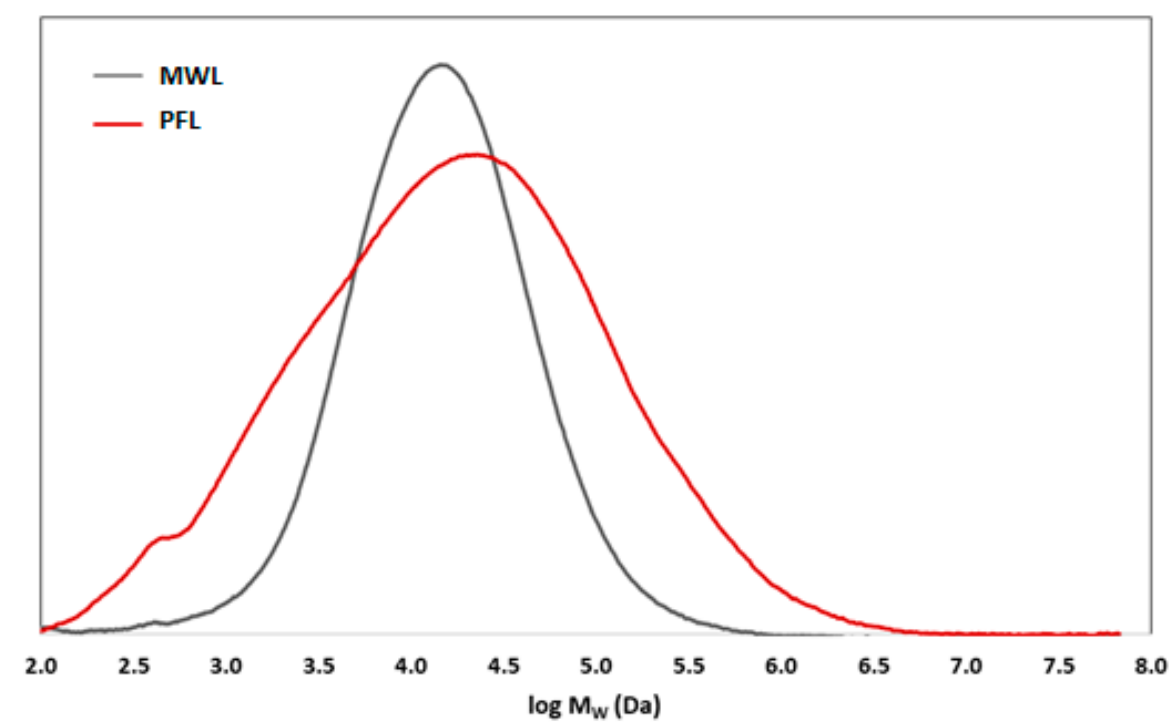

Figure 6. SEC chromatograms of MWL and PFL (the molecular weight is estimated relative to polystyrene standards). 


\subsection{Thermogravimetric Analysis of Lignins (TGA)}

The TGA was used to determine the basic behavior and thermal stability of the MWL and PFL. The processes of pyrolytic decomposition can be divided into three stages: the release of water and volatiles (from approximately 100 to $200{ }^{\circ} \mathrm{C}$ ), the rapid decomposition of the bonds that form the structure of lignin $\left(200\right.$ to $500{ }^{\circ} \mathrm{C}$ ), and a last slow carbonization to form charry residue (500 to $900{ }^{\circ} \mathrm{C}$ ). The TGA and DTG curves are shown in Figure S3 (Supplementary Material).

The first step in the thermal decomposition was qualitatively similar for both samples, although the process in MWL was faster and produced greater weight loss. The weight loss in this stage came from the release of volatile compounds and water from the samples, and their values were $7.2 \%$ and $2.8 \%$ for MWL and PFL, respectively. The most important mass change corresponded to the temperatures between 200 and $500{ }^{\circ} \mathrm{C}$, approximately, which accounted for the additional weight loss values of $32.2 \%$ for MWL and 37.5\% for PFL. In this stage, the bonds forming the structure of the lignin molecule were progressively modified, starting with the fragmentation of the interunit links [43] that were broken to release volatile oxygen compounds $\left(\mathrm{CO}, \mathrm{CO}_{2}\right.$, formaldehyde, formic acid, and some simple ethers and alkanes, among others) leaving a solid with a higher degree of unsaturation $[44,45]$. In this period, the maximum weight loss rate was located at $291{ }^{\circ} \mathrm{C}\left(0.31 \% /{ }^{\circ} \mathrm{C}\right)$ for $\mathrm{MWL}$ and $375{ }^{\circ} \mathrm{C}$ $\left(0.29 \% /{ }^{\circ} \mathrm{C}\right)$ for PFL. The significant difference between these values clearly reflected the structural changes already mentioned, suffered by the lignin in the process of delignification. The residual phase of pyrolysis $\left(500-900^{\circ} \mathrm{C}\right)$ was very slow and generated a very low rate of volatile compounds: in this phase, mass losses of 6.8 and $6.7 \%$ were measured for MWL and PFL, respectively. The percentage of non-volatilized material at $900{ }^{\circ} \mathrm{C}$ was higher in the case of PFL (53.0\%) than in MWL $(35.2 \%)$. A greater amount of non-volatile residue was related to a more branched structure (more condensed) which agreed with the spectroscopic data of the lignins studied in this work $[45,46]$.

\subsection{High Added-Value Applications for Lignin}

As an overview, the lignin obtained from the formosolv fractionation of Paulownia wood results in a high decrease in labile ether bonds, with an increase in its polydispersity, and also reflecting recondensation phenomena. However, some works reflected the chance of employing this kind of lignin for several purposes. Some applications, via a further upgrading of the lignin, may be its use as an adsorbent for heavy metal such as Pd or Cr [47] in the form of lignin nanoparticles, as well as for the manufacture of polymeric resins, polyurethanes and polyesters [48,49]. In addition, this lignin may also be used as a flocculant, cement additive, etc. On the other hand, if the lignin is employed for consequent catalytic depolymerization, it can be subjected to pyrolysis or other kinds of treatment for the production of aromatic monomers, or for the obtainment of biofuels [47]. All of these may be attractive applications for the exploitation of lignin.

\section{Conclusions}

Formosolv treatments of Paulownia, under optimum conditions, produced a cellulose-enriched pulp $(80 \%)$ and a solubilization of the $78.5 \%$ of the initial lignin in the solid. The physicochemical and spectroscopic characteristics of the formosolv lignin and its comparison with the MWL showed that the lignin underwent depolymerization phenomena but also recondensation, leading to a molecular weight distribution with high polydispersity. Delignification proceeded mainly by the breaking of $\beta-\mathrm{O}-4^{\prime}$ linkages from arylglycerol $\beta$-aryl ether units. Other bonds were also affected but resisted better the solvolytic treatment.

Supplementary Materials: The following are available online at http://www.mdpi.com/2073-4395/10/8/1205/ s1, Figure S1. Main substructures identified in the MWL and PFL of Paulownia. (A) Aryglycerol $\beta$-aryl ethers; (A') $\gamma$-OH acylated aryglycerol $\beta$-aryl ethers; (B) resinols; (C) phenylcoumarans; (D) spirodienones; (E) dibenzodioxocins; (I) cinnamyl alcohol end-groups; (J) cinnamaldehyde end-groups; (G) guaiacyl units; (S) syringyl units; $\left(\mathbf{S}^{\prime}\right)$, oxidized syringyl units bearing a carbonyl group at $\mathrm{C}_{\alpha}$; Figure S2. 1H NMR spectra of MWL and formosolv Paulownia lignin; Figure S3. TGA (dashed) and DTG (bold) curves of MWL and PFL; and 
Table S1. Assignments of carbon chemical shifts $(\delta, \mathrm{ppm})$ in ${ }^{13} \mathrm{C}$ NMR spectrum of MWL and formosolv lignin; Table S2. Assignments of ${ }^{13} \mathrm{C}-{ }^{1} \mathrm{H}$ correlation signals in the HSQC NMR spectrum of the obtained lignin fractions.

Author Contributions: Conceptualization, E.D. and A.d.V.; methodology, A.d.V.; software, E.D. and A.d.V.; validation, A.d.V. and G.G.; formal analysis, E.D., A.d.V. and G.G.; investigation, E.D.; resources, A.d.V. and G.G.; data curation, E.D., P.G.d.R. and A.d.V.; writing-original draft preparation, E.D. and A.d.V.; writing-review and editing, P.G.d.R., G.G., A.R. and P.G.; visualization, E.D., P.G.d.R., A.d.V., G.G., A.R. and P.G.; supervision, A.d.V., G.G., A.R., P.G.; project administration, A.d.V., G.G.; funding acquisition, G.G. All authors have read and agreed to the published version of the manuscript.

Funding: This research was funded by MINECO (Spain) in the framework of the projects "Development of processes for the integral use of fast-growing biomass by means of the production of bioethanol and chemical products" with reference CTQ2012-30855 and "Multistage processes for the integral benefit of macroalgal and vegetal biomass" with reference CTM2015-68503-R, by Consellería de Cultura, Educación e Ordenación Universitaria (Xunta de Galicia) through the contract ED431C 2017/62-GRC to Competitive Reference Group BV1, and by the CITACA Strategic Partnership ED431E 2018/07, programs partially funded by European Regional Development Fund (FEDER).

Acknowledgments: Pablo G. del Río would like to express his gratitude to the Ministry of Science, Innovation and Universities of Spain for his FPU research grant (FPU16/04077). Authors are grateful to Alberto Núñez and Jorge Otero from the Research Support Services of the Univeridade da Coruña for conducting and advising on the interpretation of NMR, FTIR, and TGA techniques. Finally, the authors thank Jalel Labidi and his team, from the Universidad del País Vasco, for the technical support in the analysis of SEC samples.

Conflicts of Interest: The authors declare no conflict of interest.

\section{References}

1. Morales, A.; Gullón, B.; Dávila, I.; Eibes, G.; Labidi, J.; Gullón, P. Optimization of alkaline pretreatment for the co-production of biopolymer lignin and bioethanol from chestnut shells following a biorefinery approach. Ind. Crops Prod. 2018, 124, 582-592. [CrossRef]

2. Dávila, I.; Remón, J.; Gullón, P.; Labidi, J.; Budarin, V. Production and characterization of lignin and cellulose fractions obtained from pretreated vine shoots by microwave assisted alkali treatment. Bioresour. Technol. 2019, 289, 121726. [CrossRef] [PubMed]

3. Barakat, A.; de Vries, H.; Rouau, X. Dry fractionation process as an important step in current and future lignocellulose biorefineries: A review. Bioresour. Technol. 2013, 134, 362-373. [CrossRef] [PubMed]

4. Dagnino, E.P.; Felissia, F.E.; Chamorro, E.; Area, M.C. Optimization of the soda-ethanol delignification stage for a rice husk biorefinery. Ind. Crops Prod. 2017, 97, 156-165. [CrossRef]

5. Cheiwpanich, S.; Laosiripojana, N.; Champreda, V. Optimization of organosolv based fractionation process for separation of high purity lignin from bagasse. Mater. Sci. Forum 2017, 883, 92-96. [CrossRef]

6. Zhang, K.; Pei, Z.; Wang, D. Organic solvent pretreatment of lignocellulosic biomass for biofuels and biochemicals: A review. Bioresour. Technol. 2016, 199, 21-33. [CrossRef]

7. Li, M.F.; Yang, S.; Sun, R.C. Recent advances in alcohol and organic acid fractionation of lignocellulosic biomass. Bioresour. Technol. 2016, 200, 971-980. [CrossRef]

8. Wu, K.; Shi, Z.; Yang, H.; Liao, Z.; Yang, J. Effect of ethanol organosolv lignin from bamboo on enzymatic hydrolysis of avicel. ACS Sustain. Chem. Eng. 2017, 5, 1721-1729. [CrossRef]

9. Zhang, Y.; Hou, Q.; Xu, W.; Qin, M.; Fu, Y.; Wang, Z.; Willför, S.; Xu, C. Revealing the structure of bamboo lignin obtained by formic acid delignification at different pressure levels. Ind. Crops Prod. 2017, 108, 864-871. [CrossRef]

10. Dong, L.; Zhao, X.; Liu, D. Kinetic modeling of atmospheric formic acid pretreatment of wheat straw with "potential degree of reaction" models. RSC Adv. 2015, 5, 20992-21000. [CrossRef]

11. Li, M.F.; Sun, S.N.; Xu, F.; Sun, R.C. Formic acid based organosolv pulping of bamboo (Phyllostachys acuta): Comparative characterization of the dissolved lignins with milled wood lignin. Chem. Eng. J. 2012, 179, 80-89. [CrossRef]

12. García, J.C.; Zamudio, M.A.M.; Pérez, A.; López, F.; Colodette, J.L. Search for optimum conditions of Paulownia autohydrolysis process and influence in pulping process. Environ. Prog. Sustain. Energy 2011, 30, 92-101. [CrossRef] 
13. Domínguez, E.; Romaní, A.; Domingues, L.; Garrote, G. Evaluation of strategies for second generation bioethanol production from fast growing biomass Paulownia within a biorefinery scheme. Appl. Energy 2017, 187, 777-789. [CrossRef]

14. Gong, C.; Bujanovic, B.M. Impact of hot-water extraction on acetone-water oxygen delignification of Paulownia spp. and lignin recovery. Energies 2014, 7, 857-873. [CrossRef]

15. del Río, J.C.; Rencoret, J.; Marques, G.; Gutiérrez, A.; Ibarra, D.; Santos, J.I.; Jiménez-Barbero, J.; Zhang, L.; Martínez, A.T. Highly acylated (acetylated and/or $p$-coumaroylated) native lignins from diverse herbaceous plants. J. Agric. Food Chem. 2008, 56, 9525-9534. [CrossRef]

16. Lourenço, A.; Rencoret, J.; Chemetova, C.; Gominho, J.; Gutiérrez, A.; Del Río, J.C.; Pereira, H. Lignin composition and structure differs between xylem, phloem and phellem in Quercus suber L. Front. Plant Sci. 2016, 7, 1-14. [CrossRef]

17. Blumenkrantz, N.; Asboe-Hansen, G. New Method for Quantitative Determination of Uranic Acids. Anal. Biochem. 1973, 54, 484-489. [CrossRef]

18. de Vega, A.; Ligero, P. Formosolv fractionation of hemp hurds. Ind. Crops Prod. 2017, 97, 252-259. [CrossRef]

19. Caridad, R.; Ligero, P.; Vega, A.; Bao, M. Formic acid delignification of Miscanthus sinensis. Cellul. Chem. Technol. 2004, 39, 235-244. [CrossRef]

20. Akhnazarova, S.; Kafarov, V. Experiment Optimisation in Chemistry and Chemical Engineering; MIR Publ.: Moscow, Russia, 1982.

21. Rencoret, J.; Marques, G.; Gutiérrez, A.; Nieto, L.; Jiménez-Barbero, J.; Martínez, Á.T.; José, C. Isolation and structural characterization of the milled-wood lignin from Paulownia fortunei wood. Ind. Crops Prod. 2009, 30, 137-143. [CrossRef]

22. Björkman, A. Studies on finely divided wood. I. Extraction of lignin with neutral solvents. Sven. Papperstidn. 1956, 13, 477-485.

23. Zhou, S.; Xue, Y.; Sharma, A.; Bai, X. Lignin valorization through thermochemical conversion: Comparison of hardwood, softwood and herbaceous lignin. ACS Sustain. Chem. Eng. 2016, 4, 6608-6617. [CrossRef]

24. Wen, J.L.; Sun, S.L.; Xue, B.L.; Sun, R.C. Quantitative structures and thermal properties of birch lignins after ionic liquid pretreatment. J. Agric. Food Chem. 2013, 61, 635-645. [CrossRef]

25. Constant, S.; Wienk, H.L.J.; Frissen, A.E.; De Peinder, P.; Boelens, R.; Van Es, D.S.; Grisel, R.J.; Weckhuysen, B.M.; Huijgen, W.J.; Gosselink, R.J.; et al. New insights into the structure and composition of technical lignins: A comparative characterisation study. Green Chem. 2016, 18, 2651-2665. [CrossRef]

26. Granata, A.; Argyropoulos, D.S. 2-Chloro-4,4,5,5-tetramethyl-1,3,2-dioxaphospholane, a reagent for the accurate determination of the uncondensed and condensed phenolic moieties in lignins. J. Agric. Food Chem. 1995, 43, 1538-1544. [CrossRef]

27. Balakshin, M.; Capanema, E. On the quantification of lignin hydroxyl groups with ${ }^{31} \mathrm{P}$ and ${ }^{13} \mathrm{C}$ NMR spectroscopy. J. Wood Chem. Technol. 2015, 35, 220-237. [CrossRef]

28. Wen, J.L.; Sun, S.L.; Xue, B.L.; Sun, R.C. Recent advances in characterization of lignin polymer by solution-state nuclear magnetic resonance (NMR) methodology. Materials 2013, 6, 359-391. [CrossRef]

29. Zhou, S.; Liu, L.; Wang, B.; Xu, F.; Sun, R. Microwave-enhanced extraction of lignin from birch in formic acid: Structural characterization and antioxidant activity study. Process Biochem. 2012, 47, 1799-1806. [CrossRef]

30. Sammons, R.J.; Harper, D.P.; Labbé, N.; Bozell, J.J.; Elder, T.; Rials, T.G. Characterization of organosolv lignins using thermal and FT-IR spectroscopic analysis. BioResources 2013, 8, 2752-2767. [CrossRef]

31. Babij, N.R.; McCusker, E.O.; Whiteker, G.T.; Canturk, B.; Choy, N.; Creemer, L.C.; Amicis, C.V.D.; Hewlett, N.M.; Johnson, P.L.; Knobelsdorf, J.A.; et al. NMR chemical shifts of trace impurities: Industrially preferred solvents used in process and green chemistry. Org. Process Res. Dev. 2016, 20, 661-667. [CrossRef]

32. Brandt, A.; Chen, L.; Van Dongen, B.E.; Welton, T.; Hallett, J.P. Structural changes in lignins isolated using an acidic ionic liquid water mixture. Green Chem. 2015, 17, 5019-5034. [CrossRef]

33. Sun, X.F.; Jing, Z.; Fowler, P.; Wu, Y.; Rajaratnam, M. Structural characterization and isolation of lignin and hemicelluloses from barley straw. Ind. Crops Prod. 2011, 33, 588-598. [CrossRef]

34. Xu, W.; Miller, S.J.; Agrawal, P.K.; Jones, C.W. Depolymerization and hydrodeoxygenation of switchgrass lignin with formic acid. ChemSusChem 2012, 5, 667-675. [CrossRef] [PubMed]

35. Nimz, H.; Robert, D.; Faix, O.; Nemr, M. Carbon-13 NMR spectra of lignins. Structural differences between lignins of hardwoods, softwoods, grasses and compression wood. Holzforschung 1981, 35, 16-26. [CrossRef] 
36. Gordobil, O.; Egüés, I.; Labidi, J. Modification of Eucalyptus and Spruce organosolv lignins with fatty acids to use as filler in PLA. React. Funct. Polym. 2016, 104, 45-52. [CrossRef]

37. Nitsos, C.; Stoklosa, R.; Karnaouri, A.; Vörös, D.; Lange, H.; Hodge, D.; Crestini, C.; Rova, U.; Christakopoulos, P. Isolation and characterization of organosolv and alkaline lignins from hardwood and softwood biomass. ACS Sustain. Chem. Eng. 2016, 4, 5181-5193. [CrossRef]

38. Erdocia, X.; Prado, R.; Corcuera, M.Á.; Labidi, J. Effect of different organosolv treatments on the structure and properties of olive tree pruning lignin. J. Ind. Eng. Chem. 2014, 20, 1103-1108. [CrossRef]

39. Miyagawa, Y.; Kamitakahara, H.; Takano, T. Fractionation and characterization of lignin-carbohydrate complexes (LCCs) of Eucalyptus globulus in residues left after MWL isolation. Part II: Analyses of xylan-lignin fraction (X-L). Holzforschung 2013, 67, 629-642. [CrossRef]

40. Zhu, M.Q.; Wen, J.L.; Wang, Z.W.; Su, Y.Q.; Wei, Q.; Sun, R.C. Structural changes in lignin during integrated process of steam explosion followed by alkaline hydrogen peroxide of Eucommia ulmoides Oliver and its effect on enzymatic hydrolysis. Appl. Energy 2015, 158, 233-242. [CrossRef]

41. Villaverde, J.J.; Li, J.; Ek, M.; Ligero, P.; De Vega, A. Native lignin structure of Miscanthus $x$ giganteus and its changes during acetic and formic acid fractionation. J. Agric. Food Chem. 2009, 57, 6262-6270. [CrossRef] [PubMed]

42. Ben, H.; Ferrell, J.R. In-depth investigation on quantitative characterization of pyrolysis oil by ${ }^{31} \mathrm{P}$ NMR. RSC Adv. 2016, 6, 17567-17573. [CrossRef]

43. Tejado, A.; Peña, C.; Labidi, J.; Echeverria, J.M.; Mondragon, I. Physico-chemical characterization of lignins from different sources for use in phenol-formaldehyde resin synthesis. Bioresour. Technol. 2007, 98, 1655-1663. [CrossRef] [PubMed]

44. Yang, H.; Yan, R.; Chen, H.; Lee, D.H.; Zheng, C. Characteristics of hemicellulose, cellulose and lignin pyrolysis. Fuel 2007, 86, 1781-1788. [CrossRef]

45. Wang, X.; Guo, Y.; Zhou, J.; Sun, G. Structural changes of poplar wood lignin after supercritical pretreatment using carbon dioxide and ethanol-water as co-solvents. RSC Adv. 2017, 7, 8314-8322. [CrossRef]

46. Nadji, H.; Diouf, P.N.; Benaboura, A.; Bedard, Y.; Riedl, B.; Stevanovic, T. Comparative study of lignins isolated from Alfa grass (Stipa tenacissima L.). Bioresour. Technol. 2009, 100, 3585-3592. [CrossRef]

47. Huang, D.; Li, R.; Xu, P.; Li, T.; Deng, R.; Chen, S.; Zhang, Q. The cornerstone of realizing lignin value-addition: Exploiting the native structure and properties of lignin by extraction methods. Chem. Eng. J. 2020, 402, 126237. [CrossRef]

48. Liao, J.J.; Latif, N.H.A.; Trache, D.; Brosse, N.; Hussin, M.H. Current advancement on the isolation, characterization and application of lignin. Int. J. Biol. Macromol. 2020, 162, 985-1024. [CrossRef]

49. Iravani, S.; Varma, R.S. Greener synthesis of lignin nanoparticles and their applications. Green Chem. 2020, 22, 612-636. [CrossRef]

(C) 2020 by the authors. Licensee MDPI, Basel, Switzerland. This article is an open access article distributed under the terms and conditions of the Creative Commons Attribution (CC BY) license (http://creativecommons.org/licenses/by/4.0/). 